\title{
Clinical study and analysis of orchidectomies done at Basaveshwara Teaching and General Hospital, Kalaburagi, Karnataka, India
}

\author{
Vijaykumar S. Kappikeri, Puneeth Thalasta*
}

Department of Surgery, M R Medical College, Kalaburagi, Karnataka, India

Received: 16 April 2016

Accepted: 03 June 2016

\section{*Correspondence:}

Dr. Puneeth Thalasta,

E-mail: puneeththalasta17@gmail.com

Copyright: ( ) the author(s), publisher and licensee Medip Academy. This is an open-access article distributed under the terms of the Creative Commons Attribution Non-Commercial License, which permits unrestricted non-commercial use, distribution, and reproduction in any medium, provided the original work is properly cited.

\begin{abstract}
Background: Orchidectomy is a procedure which is done sometimes as an emergency procedure and sometimes as an elective procedure and it has various psychological, physical and social considerations. This study was done to see the various modes of presentation and the need for orchidectomy in different cases and their management with respect to age, cause and its acceptance.

Methods: This retrospective study of orchidectomies was conducted in 84 patients who were admitted and treated in surgical setting from January 2012 to August 2015. Patients were evaluated thoroughly with history, physical examination, routine investigations, ultrasonography, Doppler and then subjected to orchidectomy after obtaining written and informed consent. Patients were subjected to unilateral or bilateral orchidectomy depending on the presenting condition.

Results: In this study total 84 cases who underwent orchidectomy for various reasons were studied which showed that age group between 51 to 60 years had highest incidence of orchidectomies and the majority of them were diagnosed with obstructed hernia and presented with pain as the chief complaint.

Conclusions: This study depicts that orchidectomy has to be done as an inevitable procedure in case of testicular torsion presenting late, in Fournier's Gangrene along with debridement when testis is unhealthy and facilities are limited, in cases of trauma to testis and in undescended testis presenting late. In case of recurrent and long standing hernias orchidectomy is still the best possible treatment which can be done where the facilities are minimal.
\end{abstract}

Keywords: Orchidectomy, Testicular torsion, Fournier's gangrene, Recurrent and complete hernias, Undescended testis

\section{INTRODUCTION}

Orchidectomy is the term that is used for the procedure of surgical removal of one or both testes. It is synonymous with Orchiectomy (American usage). It may be indicated for diseases of the testis both benign and malignant or injury to the testis or to control cancer of the prostate by removing a source of androgenic hormones. The removal of both testicles (bilateral orchiectomy) is the surgical form of castration.

Castration was frequently used for religious or social reasons in certain cultures in Europe, South Asia, Africa and East Asia. After battles in some cases, winners castrated their captives or the corpses of the defeated to symbolize their victory and seize their "power" and also as a mode of punishment of criminals in China. ${ }^{1}$

Some of the indications are pyocele, chronic haematocele, testicular tumour, testicular torsion, unsalvageable testicular trauma, undescended testis where testis is atrophied, as a part of herniorrhaphy (Kuntz procedure), Fournier's gangrene (in case of epididymorchitis and in rare instances animal bites. Bilateral orchidectomy is done in carcinoma prostate to achieve hormone control. 


\section{Clinical presentations in various conditions}

In undescended testis: Sterility, trauma and pain, an associated indirect inguinal hernia (70\%), torsion testis, epididymo-orchitis (as the pain will be high up it mimics acute appendicitis), testicular atrophy, malignant transformation in undescended testis is 20 times more common than normally descended testis. ${ }^{2}$ It is higher in abdominal than in inguinally located testis. Seminoma is the most common malignancy in undescended testis. ${ }^{3}$ The testis which has normally descended on other side (in case of unilateral undescended testis), is also more prone for malignant transformation than normal individual.

In pyocele: Fever, toxicity, tender swelling in the scrotum, with scrotal wall oedema.

Haematocele: Sudden onset of pain and swelling after an history of trauma (recent trauma). It is painless, hard, nontender, nonfluctuant, often calcified swelling, with loss of testicular sensation (chronic haematocele).

Testicular torsion: Sudden onset of pain in the scrotum, groin and lower abdomen, vomiting due to pylorospasm, tenderness, redness and oedema of the scrotal skin.

Fourniers gangrene: Fournier's gangrene (FG) is a fulminant form of infective necrotising fascitis of the perineal, genital, or perianal regions, which commonly affects men, but can also occur in women and children. ${ }^{4}$ Even though this clinical entity is eponymously credited to the Parisian venerologist Jean-Alfred Fournier, who described it as a fulminant gangrene of the penis and scrotum in young men, Baurienne in 1764 and Avicenna in 1877 had described the same disease earlier. ${ }^{5,6}$ Over the years, many terms have been used to describe this clinical condition including idiopathic gangrene of the scrotum, periurethral phelgmon, streptococcal scrotal gangrene, phagedena, and synergistic necrotising cellulitis. ${ }^{78}$ Very fast spreading cellulitis of scrotal skin, extending to the groin and often to anterior abdominal wall.

Dog bites to the adult scrotum are very rare. Scrotal and testicular trauma can be divided into 3 general groups: blunt, penetrating and avulsion injuries. Blunt trauma refers to injuries in which significant force is applied to the scrotum and testes. It accounts for $85 \%$ of cases. ${ }^{9}$

As a part of hernia repair: In strengthening of posterior wall (Kuntz procedure). In old people after taking consent, orchidectomy is done along with removal of entire cord, testis and total closure of posterior inguinal wall by repair so as to reduce the recurrence. Hence, it is a type of treatment employed in case of large complete and recurrent hernias.

Some of the investigations used are ultrasonography and Doppler study. Orchidectomy is the most common procedure done in all the above mentioned conditions.

\section{METHODS}

A retrospective study of all patients subjected to orchidectomy unilateral or bilateral including all emergency and elective surgeries from January 2012 to August 2015 are included in the study. Patients were evaluated with thorough history, general physical and systemic examination. Routine investigations such as complete blood counts, renal function tests, urine routine, liver function tests, ultrasonography were done in all cases and Doppler study were done in patients who presented with symptoms of ischemic orchitis. Patients were subjected to orchidectomy after taking written and informed consent.

In elective surgeries orchidectomy was done most commonly as a part of hernia repair.

In cases of torsion of testis orchidectomy was done after confirming non viability through Doppler study and its correlation with on table findings. In case of long standing hydrocele with symptoms of pyocele/ hematocele and in Fournier's gangrene unilateral or bilateral orchidectomy was done depending on the viability and condition of the testis.

In case of undescended testis patient was subjected to orchidectomy depending on the location and age of presentation to the hospital after ultarasonographic confirmation.

\section{RESULTS}

In this study total 84 cases who underwent orchidectomy for various reasons were studied which showed that age group between 51 to 60 years had highest incidence of orchidectomies and the majority of the patients who underwent orchidectomy were patients diagnosed with hernia in the form of obstructed hernia, long standing complete inguinal hernia and recurrent hernia where extensive adhesions were commonly observed and pain was the most common presenting complaint. In some cases hernia was associated with long standing hydrocele and the second major reason was for Fournier's gangrene where orchidectomy was performed in the process of extensive debridement, followed by pyocele and undescended testis then testicular torsion and lastly epididymo-orchitis.

It was observed in the study that the majority of the patients who underwent herniorrhaphy were subjected to orchidectectomy in view of dense adhesions involving the cord structures beyond dissection and all the patients recovered uneventfully and were followed up for 2 months and neither of them had any complications or any recurrence. And also were provided with psychological and moral support.

And in patients who presented with symptoms of torsion were already in the late state (gangrenous stage) and was 
confirmed through Doppler and ultrasonography and no options were left than to do orchidectomy. Similarly, in Fournier's gangrene patients presented were late who were treated with excessive debridement and orchidectomy when the testis was found to be unhealthy as an on table finding.

Table 1: Etiological factors for orchidectomy.

\begin{tabular}{|ll|}
\hline $\begin{array}{l}\text { Etiology for bilateral or } \\
\text { chidectomy }\end{array}$ & Number of cases \\
\hline Fournier's gangrene & 3 \\
\hline Epididymo-orchitis & 1 \\
\hline Testicular torsion & 1 \\
\hline Obstructed hernia & 1 \\
\hline Pyocele & 1 \\
\hline Total & $\mathbf{7}$ \\
\hline $\begin{array}{l}\text { Etiology for unilateral or } \\
\text { chidectomy }\end{array}$ & Number of cases \\
\hline Fournier's gangrene & 9 \\
\hline Epididymo orchitis & 1 \\
\hline Testicular torsion & 3 \\
\hline $\begin{array}{l}\text { Obstructed hernia/Recurrent hernia/ } \\
\text { Herniorrhaphy }\end{array}$ & 43 \\
\hline Pyocele & 9 \\
\hline Undescended testis & 10 \\
\hline Animal bites (dog/pig) & 1 \\
\hline Total & $\mathbf{7 7}$ \\
\hline
\end{tabular}

Table 2: Age wise distribution of number of cases who underwent orchidectomy.

\begin{tabular}{|ll|}
\hline Age distribution & Number of orchidectomies \\
\hline$\leq 10$ years & 3 \\
\hline $11-20$ years & 8 \\
\hline 21-30 years & 9 \\
\hline 31-40 years & 6 \\
\hline 41-50 years & 14 \\
\hline $51-60$ years & 26 \\
\hline 61-70 years & 16 \\
\hline 70 years and above & 2 \\
\hline Total & $\mathbf{8 4}$ Cases \\
\hline
\end{tabular}

Table 3: Symptoms of presentation.

\begin{tabular}{|ll|}
\hline Symptom & Number of cases presenting \\
\hline Inguino scrotal swelling & 52 \\
\hline Pain & 76 \\
\hline Vomiting & 40 \\
\hline Fever & $\mathbf{2 8}$ \\
\hline
\end{tabular}

\section{DISCUSSION}

In the present era of organ preserving and minimally invasive surgeries, it is interesting to find that a sizable proportion of our patients had underwent orchidectomy for various etiological reasons. This underscores the fact that in a developing country like India orchidectomy is still performed in large numbers as a common procedure in peripheral hospital and in rural settings.

Orchidectomy is a procedure which is done sometimes as an emergency procedure and sometimes as an elective procedure and it has various psychological, physical and social considerations. Following are the various etiological reasons for which orchidectomy were done in our hospital setting.

\section{Orchidectomy as a part of hernia repair}

Even though the modern methods of hernia repair suggest no benefits of orchidectomy. ${ }^{10}$ But still, it can be employed as a modality of treatment in financially backward areas and in settings where advanced facilities are not available.

In our study majority of the patients who presented had long standing complete hernia and some had symptoms of obstruction or gangrene at presentation. Two patients underwent hernia repair along with orchidectomy and resection and anastomosis of the gangrenous bowel. And the other reason where orchidectomy was performed was in case of recurrent hernia due to dense adhesions involving the cord structures which was difficult for dissection. All the patients who underwent hernia repair along with orchidectomy were followed up on outpatient basis for two months and neither of them had any complications.

\section{Fournier's gangrene (FG)}

Initially, FG was defined as an idiopathic entity, but diligent search will show the source of infection in the vast majority of cases, as either perineal or genital skin infections. Anorectal or urogenital and perineal trauma, including pelvic and perineal injury or pelvic interventions are other causes of FG. ${ }^{11}$ The most common foci include the gastrointestinal tract $(30 \%-50 \%)$, followed by the genitourinary tract $(20 \%-40 \%)$, and cutaneous injuries $(20 \%)$.

Comorbid systemic disorders are being identified more and more in patients with FG, the commonest being diabetes mellitus and alcohol misuse. Diabetes mellitus is reported to be present in $20 \%-70 \%$ of patients with FG and chronic alcoholism in $25 \%-50 \%$ patients. $^{12,13}$ The emergence of HIV into epidemic proportions has opened up a huge population at risk for developing FG. ${ }^{14}$

In our setup majority of the patients who were diagnosed with Fournier's gangrene were mostly from the rural areas and had associated comorbidities like diabetes mellitus. All the patients were managed by excessive debridement and orchidectomy depending on the viability 
of testis which in most cases was nonviable. And later skin grafting and secondary suturing was done.

Early series reported high mortality rates around $80 \%$, but more recent studies show an improvement with lower rates of generally less than $40 \% .^{12,15}$ Despite better understanding of the aetiopathogenesis of the disease, the availability of more broader spectrum antimicrobials, and the trend towards early and timely surgical intervention, the continuing high mortality rate reflects the potentially devastating nature of this disease. Factors that have been identified to negatively affect survival include age, primary anorectal source of infection, delay in treatment, and immunocompromised state. ${ }^{16}$ There is as yet inconclusive evidence to suggest that diabetes or number of surgical debridement's adversely affects the prognosis. $^{17}$

Even though the management of Fournier's gangrene involves liberal excision of all the slough, placement of testis in medial aspect of thigh and skin grafting once wound is granulated and in many cases testis is usually preserved as it is viable. Here, in our study due to lack of awareness among patients, who majority were from rural and economically backward areas, presented late and it was extensively involving the testis and were treated with debridement and orchidectomy and subsequently all patients improved and were discharged. Hence, orchidectomy can be considered as a treatment modality for Fournier's gangrene when the disease is involving the testis extensively and also in economically backward areas where facilities are not available.

\section{Undescended testis}

Undescended testis is the commonest genital malformation in boys. Although the mechanism that regulates prenatal testicular descent is still partly obscure, there is persuasive evidence that endocrine, genetic, and environmental factors are involved. ${ }^{18}$ The treatment of undescended testis should begin after six months and ideally be completed by the child's first birthday. ${ }^{19}$

Men with untreated bilateral cryptorchidism suffer from impaired fertility. Early treatment can potentially minimize the risk of infertility, although treatment before the age of 13 doesn't appear to lessen the risk of malignancy. ${ }^{20}$ For adults, there is no consensus recommendation although it is known that undescended testis, even if successfully treated, may have long-term consequences for testicular function and the development of testicular cancer. The latter applies especially to boys in whom treatment is delayed. ${ }^{20}$

In our study majority of the patients who presented were in the age group 15-25 or above and the reasons for consultation was pain in the inguinal region or association with hernia. And all the patients had on table finding of atrophied testis and in most cases testis was located in the inguinal region. This shows that due to lack of awareness patients usually presented late and orchidectomy was only the treatment option left than orchidopexy.

\section{Dog bite}

It is estimated that 740 people per 100000 are bitten by dogs every year. ${ }^{21}$ Of these, $50 \%$ are children and an average of 2.6 per 100000 require hospital admission. Injuries to the external genitalia, in particular to the scrotum, following dog bites are rare when compared to the total number of dog bites. ${ }^{22,23}$ In our study dog bite involving the scrotum was extensive and the testis was unsalvageable and the patient ended up with orchidectomy.

\section{Orchidectomy in pyocele or hydrocele or haematocele}

In our study majority of the patients presented with long standing hydrocele usually more than 5 years and had symptoms like fever with raised counts and some others had an history of old testicular trauma. All these patients were subjected to orchidectomy after confirmation of unhealthy testis on table. All the patients recovered uneventfully.

\section{CONCLUSION}

In case of recurrent and long standing complete hernias orchidectomy is still the best possible treatment which can be done. Orchidectomy is more likely to be associated with repair of complicated hernias and that permission for possible orchiectomy should be obtained from these patients preoperatively. On the other hand, consent for orchiectomy and detailed discussion is unwarranted for patients with primary reducible hernias. In addition, orchidectomy during herniorrhaphy should be limited to cases of specific testicular and cord abnormalities, and the reason for orchidectomy should be clearly documented in the operative record.

The rare case which was subjected to orchidectomy was a case of dog bite which shows that even though dog bites are common but dog bites involving scrotum or external genitalia should not be overlooked.

This study represents the various reasons for orchidectomy which can be considered and also the patients acceptance and proper counselling along with psychological and moral support which is a must for young patients undergoing orchidectomy.

\section{ACKNOWLEDGEMENTS}

We like to provide special thanks to the medical records department for providing all the file records needed for the study.

\section{Funding: No funding sources Conflict of interest: None declared Ethical approval: Not required}




\section{REFERENCES}

1. Faber E. Chronological hand book of the history of China: a manuscript left by the late Rev. Ernst Faber. General Evangelical Protestant missionary society of Germany; 1902:3.

2. Virtanen HE, Cortes D, Raipert-De Mayts E, Ritzen M, Nordenskjoid A, Skakkebaek NE Toppari J: Development and descent of the testis in relation to cryptorchidism. Acta Paediatr. 2007;96:622-7.

3. Pettersson A, Richiardi L, Nordenskjoid A, Kaijser M, Akre O: Age at surgery for undescended testis and risk of testicular cancer. $N$ Engl $J$ Med. 2007;356(18):1835-41.

4. Smith GL, Bunker CB, Dineeen MD. Fournier's gangrene. Br J Urol 1998;81:347-55, .

5. Fournier J-A. Gangrene foudroyante de la verge. Semaine Medicale. 1883;3:345-8.

6. Nathan B. Fournier's gangrene: a historical vignette. (Letter). Can J Surg. 1998;41:72.

7. Gray JA. Gangrene of the genitalia as seen in advanced periurethral extravasation with phlegmon. J Urol. 1960;84:740-5.

8. Meleney FL. Hemolytic streptococcus gangrene. Arch Surg. 1924;9:317-64.

9. Santucci RA, Battino BS, Terlecki RP. Testicular trauma. http://www.emedicine.com/med/ topic2859.htm. Accessed November 27, 2008.

10. Abrahamson J. Etiology and pathophysiology primary and recurrent groin hernia formation Surg Clin North Am. 1998;78(6):953-70.

11. Eke N. Fourniers gangrene: a review of 1726 cases. Br J Surg 2000;87:718-28.

12. Morpurgo E, Galandiuk S. Fournier's gangrene. Surg Clin N Am. 2002;82:1213-24.

13. Clayton MD, Fowler JE Jr, Sharifi R. Causes, presentation and survival of fifty-seven patients with necrotizing fasciitis of the male genitalia. Surg Gynecol Obstet. 1990;170:49-55.

14. Johnin K, Nakatoh M, Kadowaki T, Kushima M, Koizumi S, Okada Y. Fournier's gangrene caused by
Candida species as the primary organism. Urology. 2000;56:153.

15. Stephens BJ, Lathrop JC, Rice WT, Gruenberg JC. Fournier's gangrene: historic (1764-1978) versus contemporary (1979-1988) differences in aetiology and clinical importance. Am Surg. 1993;59:149-54.

16. Martinelli G, Alessandrino EP, Bernasconi P, Caldera D, Colombo A, Malcovati L, et al. Fournier's gangrene: a clinical presentation of necrotizing fasciitis after bone marrow transplantation. Bone Marrow Transplant. 1998;22:1023-6.

17. Nisbet AA, Thompson IM. Impact of diabetes mellitus on the presentation and outcomes of Fournier's gangrene. Urology. 2002;60:775-9.

18. Virtanen HE, Cortes D, Raipert-De Mayts E, Ritzen M, Nordenskjoid A, Skakkebaek NE,et al. Development and descent of the testis in relation to cryptorchidism. Acta Paediatr. 2007;96:622-7.

19. Leitlinie der Deutschen Gesellschaft für Kinderchirurgie, der Deutschen Gesellschaft für Urologie und der Deutschen Gesellschaft für Kinderund Jugendmedizin, vertreten durch die Arbeitsgemeinschaft für pädiatrische Endokrinologie (APE) (2008): Hodenhochstand - Maldeszensus testis. Www.uni-duesseldorf.de/AWMF/11/006022.htm

20. Pettersson A, Richiardi L, Nordenskjoid A, Kaijser M, Akre O: Age at surgery for undescended testis and risk of testicular cancer. $\mathrm{N}$ Engl $\mathrm{J}$ Med. 2007;356(18):1835-41.

21. Wolff K. Management of animal bite injuries of the face: experience in 94 patients. J Oral Maxillofac Surg. 1998;56:838-43.

22. Morgan M, Palmer J. Dog Bites. BMJ. 2007;334:413-7.

23. Van der Horst C, Martinez-Portillo FJ, Seif C, Groth W, Jünemann KP. Male genital injuries: Diagnosis and treatment. BJU Int. 2004;93:927-30.

Cite this article as: Kappikeri VS, Thalasta P R. Clinical study and analysis of orchidectomies done at Basaveshwara Teaching and General Hospital Kalaburagi, Karnataka, India. Int Surg J 2016;3:1460-4. 